\title{
Spare parts neoumbilicoplasty
}

\author{
William D. Tobler Jr, Kelly N. Nicholas, Carolyn De La Cruz \\ Department of Plastic Surgery, University of Pittsburgh Medical Center, Pittsburgh, PA, USA
}

Umbilical preservation can be challenging, particularly in complex cases involving simultaneous ventral hernia repair and abdominoplasty. Although the umbilicus serves no functional purpose, removal of the umbilicus can draw unwanted attention to the abdominal area and can cause emotional distress to patients. There are several well documented options for umbilical reconstruction. We present a new umbilical reconstruction technique relevant for such cases. This neoumbilicoplasty allows for preservation of the original umbilicus with relocation and reconstruction using local flaps. The technique is relatively simple and the time needed is minimal. The result is a natural, well positioned umbilicus using the principles of spare part surgery.

Keywords Abdominoplasty / Umbilicus / Herniorrhaphy
Correspondence: Kelly N. Nicholas Department of Plastic Surgery, University of Pittsburgh Medical Center, 3380 Blvd of the Allies, Suite 158, Pittsburgh, PA 15213, USA

Tel: +1-412-641-3962

Fax: +1-412-641-1149

E-mail: snyderkn@upmc.edu

Received: 30 Jun $2018 \bullet$ Revised: 4 Oct $2018 \bullet$ Accepted: 11 Oct 2018

pISSN: 2234-6163 • elSSN: 2234-6171 • https://doi.org/10.5999/aps.2018.00794 • Arch Plast Surg 2019;46:371-374

\section{INTRODUCTION}

The umbilicus requires special attention during surgery for abdominal wall reconstruction or aesthetic abdominoplasty. Transposition of the umbilicus using its original blood supply (subdermal plexus or periumbilical perforators) is often possible and preferable. However, in situations, such as umbilical hernia repair or massive panniculectomy, where the umbilicus needs to be excised completely, it is often discarded and in some cases reconstructed at a later date.

There are several different techniques described in the literature for umbilicoplasty and neoumbilicoplasty. A new technique is presented for preservation of the umbilicus in which the umbilicus is excised completely and reconstructed as a full thickness graft onto local skin flaps. This technique allows use of native tissue and helps to maintain the unique characteristics of the abdomen.

\section{CASE}

A 57-year-old man presented for evaluation of an incisional her- nia and panniculus in April 2016 (Fig. 1). He had a history of laparoscopic gastric bypass 6 years prior and a $54 \mathrm{~kg}$ weight loss. His height and weight at presentation were $175 \mathrm{~cm}$ and $90 \mathrm{~kg}$, respectively. He was stable at this weight for 3 years and was a non-smoker. In addition to the gastric bypass, surgical history was significant for lap-assisted ileocoloectomy and primary repair of a recurrent umbilical hernia in 2015 for perforated bowel which occurred during colonoscopic polypectomy, primary repair of an umbilical hernia in 2007, and a laparoscopic cholecystectomy in 1997.

On physical exam, he had a well healed midline incision with reducible ventral hernia and umbilical hernia with a hanging panniculus. Abdominal computerized tomography scan showed a midline "Swiss cheese" fascial defect and a left sided periumbilical hernia. The surgical plan included open ventral hernia repair with general surgery in combination with abdominoplasty by plastic surgery. After thorough discussion of the risks, benefits, and alternatives to surgery, the patient was consented for the procedure.

Intraoperatively, the hernia extended the length of the previous widened midline incision with the sac densely adhered to

Copyright $\odot 2019$ The Korean Society of Plastic and Reconstructive Surgeons

This is an Open Access article distributed under the terms of the Creative Commons Attribution Non-Commercial License (http://creativecommons.org/

licenses/by-nc/4.0/) which permits unrestricted non-commercial use, distribution, and reproduction in any medium, provided the original work is properly cited. I www.e-aps.org 


\section{Fig. 1. Preoperative and postoperative photos}

(A) Preoperative photo demonstrating midline incision with hanging panniculus. (B) Postoperative image shows well healed neoumbilicus at postoperative 3 months.
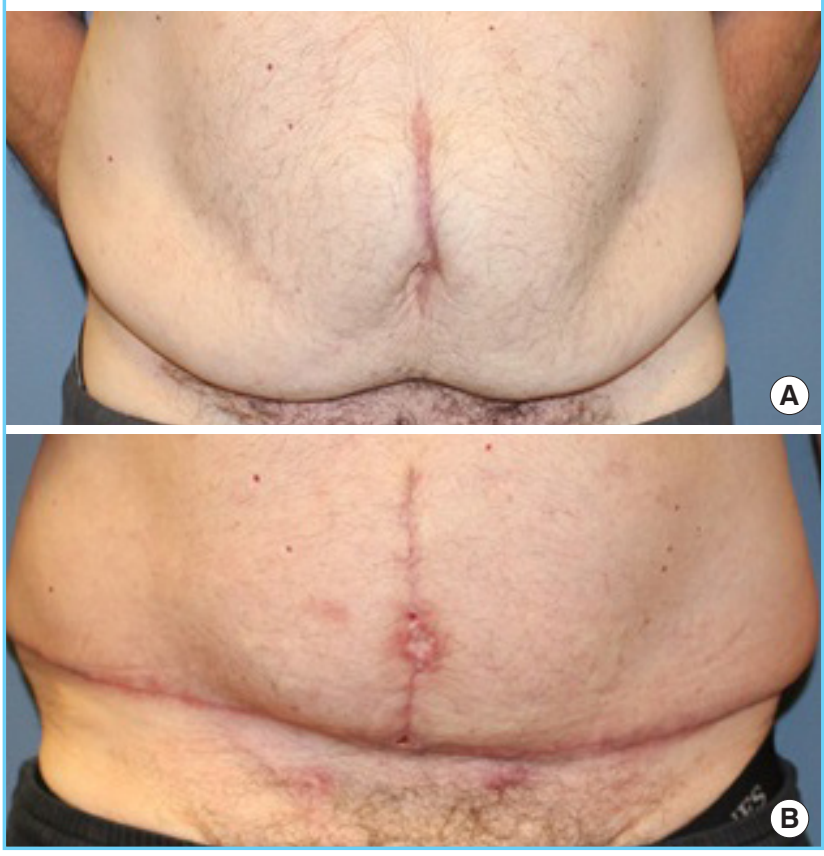

Fig. 2. Umbilicus completely excised prior to inset

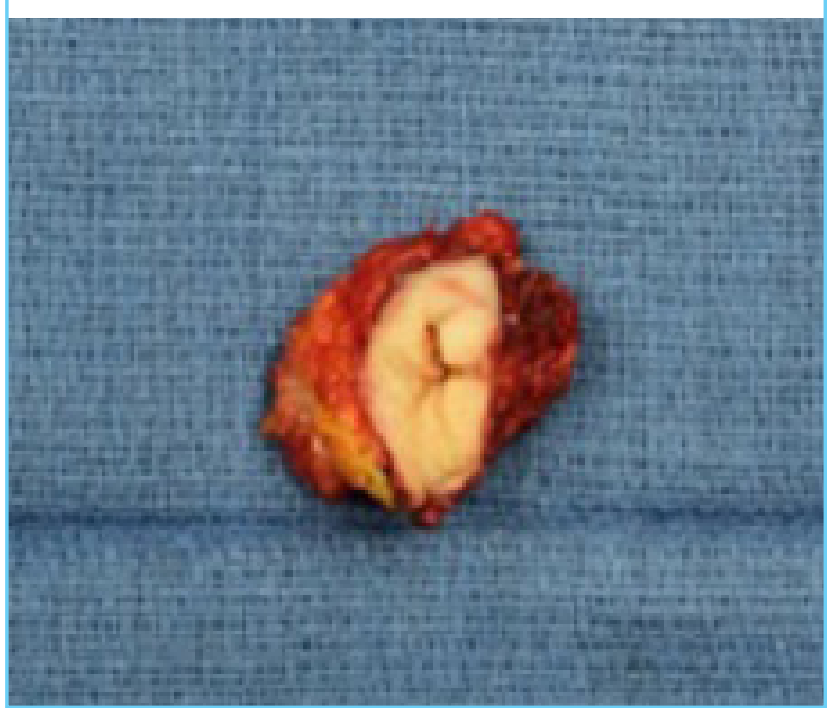

the umbilical stalk. The initial surgical plan was to sacrifice the umbilicus, but the decision was made intraoperatively to use the original tissue as a skin graft. Therefore, the umbilicus was excised and placed on the back table (Fig. 2). The hernia sac was excised and the edges of the anterior rectus sheath were separated from the posterior rectus sheath. The fascia was then closed primarily without any undo tension. A fleur-de-lis abdominoplasty was performed with removal of the panniculus and exci-

\section{Fig. 3. Intraoperative photos \\ (A) The de-epithelialized flap prior to inset. (B) The flap and umbili- cus after inset.}
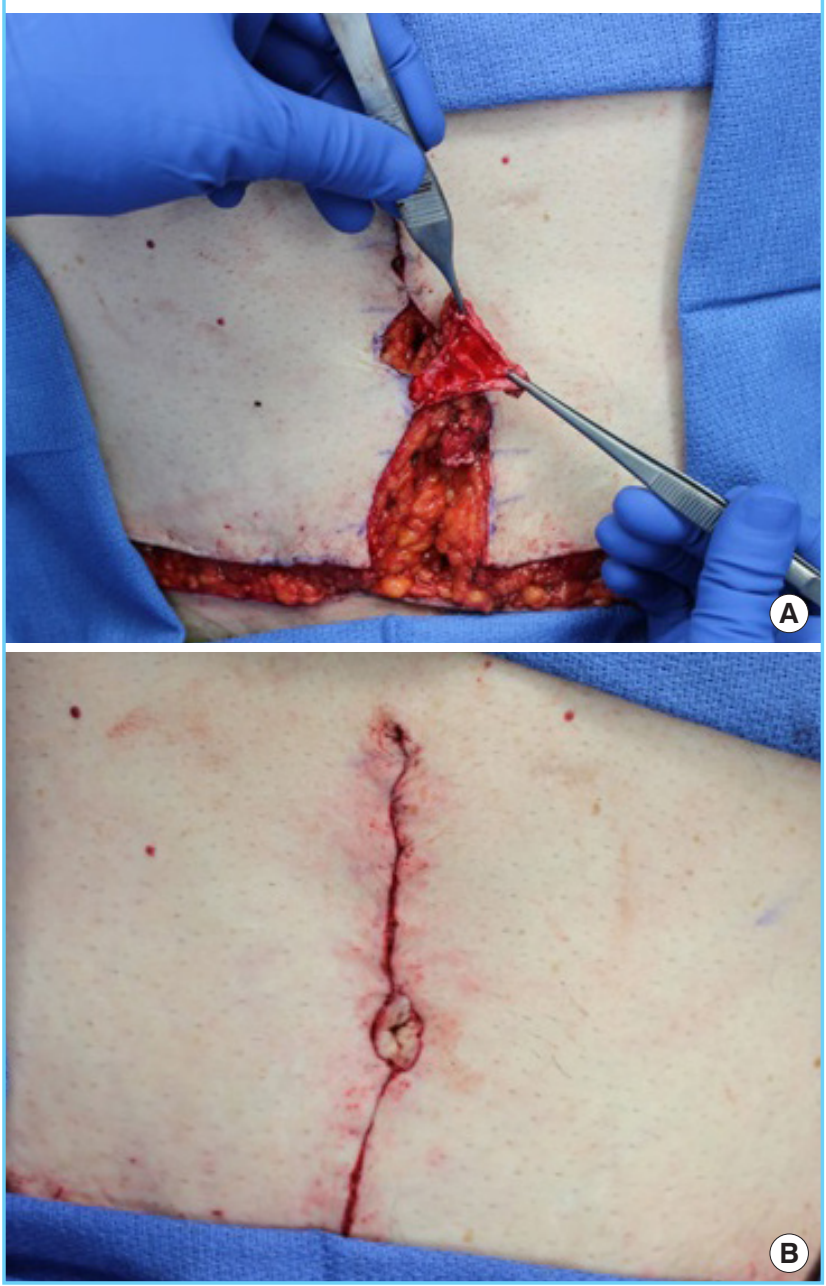

sion of the previous midline scar. In order to create a neoumbilicus, a flap of skin and subcutaneous tissue from each abdominal flap was created and de-epithelialized to provide a vascular bed for the graft to adhere (Fig. 3). This was made using a 3:1 flap design and the flaps were approximately $2 \times 6 \mathrm{~cm}$ each. These flaps were sutured together and then secured to the anterior $a b-$ dominal fascia using 3-0 polyglactin suture. The excised umbilicus was thinned to the dermis on the back table and reapplied to the de-epithelialized flaps as a full thickness graft. A 3-0 polyglactin suture was used to attach the undersurface of the umbilicus to the deep crevasse of the flaps and anterior abdominal wall (Fig. 3). The graft was sutured around its perimeter with 5-0 polypropylene followed by application of a Xeroform bolster.

The patient tolerated the procedure well. At his initial post-op visit, he demonstrated $100 \%$ take of his free umbilical graft. At 9 months postoperatively, his abdomen was free of recurrent hernia and his umbilicus was well healed with an acceptable cos- 


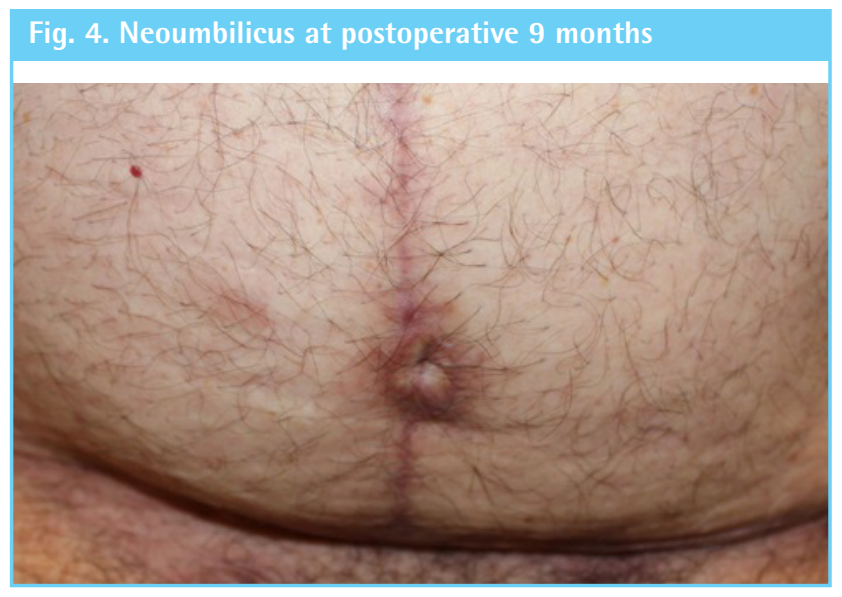

metic outcome as judged by shape, size, and position of the umbilicus (Fig. 4).

\section{DISCUSSION}

The functional importance of the umbilicus is served in utero and stands as a scarred remnant of the umbilical cord ligated at birth. The irregular topography of the umbilicus is created, in part, by ligament contracture from the remnant structures of the umbilical cord as well as the effects of gravity [1]. In 1939, Thorek [2] states that "someone has expressed the thought that an abdomen without a navel is like a face without a nose." Total removal of the umbilicus can draw unwanted attention to that area and lead to emotional distress for patients [3]. Therefore, its preservation or recreation is important.

The ideal umbilicus is vertically oriented and oval-shaped. Superior hooding, although not always present, is preferred by patients [4]. Often thought of as a midline structure, a detailed anatomical study showed that the umbilicus is actually rarely found midline [5]. Positioning of the umbilicus is a key factor for a successful abdominoplasty. One of the most clinically useful anatomic landmarks for umbilical repositioning is the superior level of the iliac crest [3]. Positioning of the umbilicus can also be achieved using the umbilicopubic distance, which on average ranges from 15.04 to $16.2 \mathrm{~cm}$ [3].

There are many reports in the literature about how to create the umbilicus during abdominoplasty. The classic transposition is performed most commonly in conjunction with abdominoplasty [6-10]. A floating umbilical technique is often performed with a limited abdominoplasty. Other techniques described include a "scarless" umbilicoplasty which attempts to hide the scar [11]. Castillo et al. [12] described adding a de-epithelialized flap to reinforce the transposed umbilicus using a Y-shaped design. Rozen and Redett [13] described a two-dermal-flap tech- nique.

Combining the concept of local flaps and skin grafts, we reconstructed an umbilicus as a free graft onto a vascularized wound bed. Although there are numerous options for umbilical reconstruction, we feel this option is superior because it uses the patient's own tissue and results in a more natural appearing umbilicus. The time needed to make the flaps and thin the graft is minimal and the technique is relatively simple. Furthermore, our method combines concepts from other well described procedures which are common knowledge to practicing plastic surgeons.

In cases where increased superior hooding is desired, a larger graft can be tacked to the anterior fascia for added depth. In our case, the base of the neoumbilicus was sutured centrally in the defect to the anterior fascia with minimal hooding. Due to the circumferential design of the graft and inset, the neoumbilicus can be subject to cicatricial scarring formation; however, our final result was reasonable and acceptable to both the surgeon and the patient.

In the event that an umbilicus needs to be excised, we believe there is no reason to discard the native tissue. An umbilicus can be recreated simply and effectively by performing this spare parts technique as described. Ultimately, this is a simple solution that prevents the awkward appearance of an abdomen void of its original characteristic landmark.

\section{NOTES}

\section{Conflict of interest}

No potential conflict of interest relevant to this article was reported.

\section{Ethical approval}

The study was performed in accordance with the principles of the Declaration of Helsinki. Written informed consents were obtained.

\section{Patient consent}

The patient provided written informed consent for the publication and the use of his images.

\section{Author contribution}

Data acquisition, analysis, and interpretation: Tobler WD. Drafting of the manuscript, critical revision of the manuscript, editing and submission of manuscript: Nicholas KN. Study supervision: Carolyn De La Cruz: surgeon. Approval of final manuscript: all authors. 


\section{ORCID}

William D. Tobler Jr https://orcid.org/0000-0003-0106-0948

Kelly N. Nicholas https://orcid.org/0000-0001-8961-193X

Carolyn De La Cruz https://orcid.org/0000-0003-3424-9747

\section{REFERENCES}

1. Southwell-Keely JP, Berry MG. Umbilical reconstruction: a review of techniques. J Plast Reconstr Aesthet Surg 2011;64: 803-8.

2. Thorek M. Plastic reconstruction of the female breasts and abdomen. Am J Surg 1939;43:268-78.

3. Rodriguez-Feliz JR, Makhijani S, Przybyla A, et al. Intraoperative assessment of the umbilicopubic distance: a reliable anatomic landmark for transposition of the umbilicus. Aesthetic Plast Surg 2012;36:8-17.

4. Joseph WJ, Sinno S, Brownstone ND, et al. Creating the perfect umbilicus: a systematic review of recent literature. Aesthetic Plast Surg 2016;40:372-9.

5. Rohrich RJ, Sorokin ES, Brown SA, et al. Is the umbilicus truly midline? Clinical and medicolegal implications. Plast Reconstr Surg 2003;112:259-63.
6. Delerm A. Refinements in abdominoplasty with emphasis on reimplantation of the umbilicus. Plast Reconstr Surg 1982;70:632-7.

7. Pitanguy I. Abdominal lipectomy. Clin Plast Surg 1975;2: 401-10.

8. Choudhary S, Taams KO. Umbilicosculpture: a concept revisited. Br J Plast Surg 1998;51:538-41.

9. Juri J, Juri C, Raiden G. Reconstruction of the umbilicus in abdominoplasty. Plast Reconstr Surg 1979;63:580-2.

10. Malic CC, Spyrou GE, Hough M, et al. Patient satisfaction with two different methods of umbilicoplasty. Plast Reconstr Surg 2007;119:357-61.

11. Bruekers SE, van der Lei B, Tan TL, et al. "Scarless" umbilicoplasty: a new umbilicoplasty technique and a review of the English language literature. Ann Plast Surg 2009;63:1520.

12. Castillo PF, Sepulveda CA, Prado AC, et al. Umbilical reinsertion in abdominoplasty: technique using deepithelialized skin flaps. Aesthetic Plast Surg 2007;31:519-20.

13. Rozen SM, Redett R. The two-dermal-flap umbilical transposition: a natural and aesthetic umbilicus after abdominoplasty. Plast Reconstr Surg 2007;119:2255-62. 